\title{
Predictive value of horizon scanning for future scenarios
}

\author{
Yuichi Washida and Akihisa Yahata
}

\begin{abstract}
Purpose - The purpose of this study is to measure the predictive value of future scenarios prepared using horizon scanning. The future scenarios prepared at the initiative of the Japanese Government have had low predictive value. They have frequently failed to contribute to industrial development and caused social loss. Horizon scanning, which is a key methodology applied in foresight activities, has begun to be used in countries as part of their national innovation systems in lieu of conventional forecasting methods based on the assumption of technological innovation. Research was conducted to actually measure the predictive value of future scenarios prepared using horizon scanning.
\end{abstract}

Design/methodology/approach - An online survey in Japan was conducted on ordinary people's attitudes. The questionnaires presented 20 scenarios regarding future society, which were created with the conventional method or horizon scanning method.

Findings - Survey results verified that horizon scanning-based scenarios provided significantly higher predictive value than scenarios prepared using conventional methods.

Practical implications - Implication 1: By eliminating bias in input data and perspectives adopted when considering scenarios, it may be expected that scenarios will be derived that have even higher "predictive value." Implication 2: By setting the layers of anticipated outputs high and the fields broad, it may be expected that scenarios will be derived that have even greater "change."

Originality/value - The relatively high rate for the predictive value of the horizon scanning method, more than $40 \%$, validated in this study was significant.

Keywords Horizon scanning, Predictive value, National innovation system, Scenarios, Technology roadmap, Backcasting

Paper type Research paper

\section{Penetration of the scenario method in decision-making}

Due to the risks entailed in predictions about science and technology and their social impact where considerable social loss may be incurred if the predictions are wrong, a recognition has gradually become more pervasive of the importance of having multiple scenarios prepared, which are then compared and scrutinized. The school of emergent strategy exemplified by Henry Mintzberg et al. (1999) underscores the effectiveness of using diverse scenarios in corporate strategic decision-making. Wack (1985) presented a famous case of Royal Dutch Shell's adoption of scenario planning, which made use of the scenario method to facilitate the formulation of a mid- and long-term strategy that enabled the company to properly prepare and address the upheaval of oil interests as they shifted from the USA and European majors to organization of the petroleum exporting countries (OPEC). Wack also served as an important turning point, promoting more widespread use of the scenario method. Meissner and Wulf (2013) conducted experiments in large business workshops of a variety of configurations to compare conventional strategy formulation and the scenario method. Their results verified that the scenario method reduced cognitive biases resulting from the framing effect in strategy
Yuichi Washida is based at the School of Business

Administration,

Hitotsubashi University, Tokyo, Japan.

Akihisa Yahata is based at

the Future Design

Laboratory, Japan

Research Institute Ltd,

Shinagawa-ku, Japan.

Received 9 May 2020 Revised 28 July 2020 Accepted 31 July 2020

(C) Yuichi Washida and Akihisa Yahata. Published by Emerald Publishing Limited. This article is published under the Creative Commons Attribution (CC BY 4.0) licence. Anyone may reproduce, distribute, translate and create derivative works of this article (for both commercial and non-commercial purposes), subject to full attribution to the original publication and authors. The full terms of this licence may be seen at http://creativecommons. org/licences/by/4.0/legalcode 
formulation, increased confidence in decision-making and improved the quality of strategy formulation.

Nevertheless, there are also some aspects relating to the utility of the scenario method that are still being debated. Phadnis et al. (2015) conducted similar experiments with large business workshops and reported that they were unable to obtain results indicating that the use of the scenario method increased participants' confidence in decision-making. However, Phadnis et al. verified that the scenario method increased the flexibility of strategy formulation.

Of such decision-making techniques using the scenario method, this study focuses on horizon scanning, which has increasingly been used in countries around the world and attempts to validate its effectiveness.

\section{Predictive value as a core issue relating to dissemination of the scenario method}

There have been long-standing controversies over the government's future scenarios, especially in Japan. A major problem is their low predictive value in cases where future uncertainty has been so extensive about the object to be predicted. For instance, the Japanese government's technology prediction about the rapid diffusion of mobile and smartphones over the past 20 years was a major failure. According to a government technology forecast report (The Economic Planning Agency Planning Bureau, 1991), the Japanese government predicted at the time that, if there were a breakthrough in the domestic personal communication market, the market scale would be on the order of approximately US\$2bn in the year 2000 and US\$5bn in the year 2010. However, the actual total market size for personal-use mobile phones in 1999 was approximately US\$10bn and, by 2005, it had already surpassed US\$20bn. The mobile phone market grew more than five times the level predicted by the Japanese government. This was a clear example of a technology forecast failure. Subsequently, this failure resulted in substantial social loss. With many Japanese companies forced to give up their mobile and smartphone markets in the early period of the market growth, observers have been pointed out that a national vision was lacking about how this market would become the future core of the electronics industry.

There are numerous other examples of the Japanese government's technology forecast failures. Because of these failures, Japanese policymakers and scientists have tended to be overly sensitive about the predictive value of forecasts and scenarios. Even in cases where a stance has been adopted of comparing and scrutinizing multiple scenarios, there has been a strong hope that some of these scenarios turn out to be accurate. However, a dilemma arises in that the more overly sensitive one becomes about scenarios' predictive value, the more one clings to past successes, trusts only deductive evidence and tends to be shortsighted pursuing successes that other countries have achieved. The issue of scenario predictive value is extremely difficult.

Many of these technology forecasts have been prepared based upon the technology roadmap method. The main aim of the technology roadmap method is to present a variety of "desired futures" and thereby indicate processes for technology development. However, a look at the aforementioned examples from Japan shows that one must also take into account negative effects in cases where many of these are outliers.

What sort of evidence needs to be acquired so that we may conclude that a scenario has definitely been correct? In conventional technology prediction, if a certain technology is implemented, then the technology development scenario has been regarded as successfully predicting the future. For example, in the case of technology development scenarios prepared using the Delphi method (Udagawa and Hanazato, 2001), the predictive value may be said to be the same as the rate of implementation. Generally, the rate of implementation is measured factually based upon whether or not companies or research institutions have introduced into the market products or services using the technology. It should be noted that the degree of market diffusion of such products or services is irrelevant. The reason is that the Delphi method does

PAGE 18 FORESIGHT | VOL. 23 NO. 12021 
not include a means for measuring market diffusion. Even studies on maps and competitiveness of scientific and technological research only discuss such matters up to implementation and have not focused on the subsequent rate of market diffusion (Saka et al., 2010). In cases where the rate of success of foresight is considered mainly in terms of the rate of implementation, it is important what percentage of a large group of scenarios has been implemented, but, in cases where the rate of success of foresight is considered mainly in terms of the rate of diffusion, the important thing is how many people in society are using the technology. In other words, the rate of implementation assumes the point of view of the supplier while the rate of diffusion adopts the perspective of the user's side.

In the aforementioned mobile phone example, the essence of the issue of the oversensitivity of Japan's policymakers and scientists relates not to the rate of implementation, but to the rate of diffusion. Or rather, the core of the issue is precisely the social change realized as a result of the diffusion of mobile internet technology. Consequently, it should be noted that the rate of implementation, which has been used in conventional technology predictions, does not provide a sufficient answer to the issue of policymakers' and scientists' oversensitivity. Accordingly, this study defines the predictive value of scenarios as something that must be measured in layers of social change or at a minimum, in such industry or business layers.

\section{What is horizon scanning?}

Horizon scanning is based upon a methodology for creating scenarios about social change that was devised and developed by the Stanford Research Institute in the 1960s (Loveridge, 2008). The technique is based on politics, economics, society, and technology (PEST) analysis (Aguilar, 1967), which had previously been used. As shown in Figure 1, horizon scanning collects a large amount of information (weak signals) that are "future sprouts" laying outside the extension of the current status-quo line so as to consider and examine diverse scenarios about social change that might occur in the future. In

\section{Figure 1 How horizon scanning collects "weak signal" information}

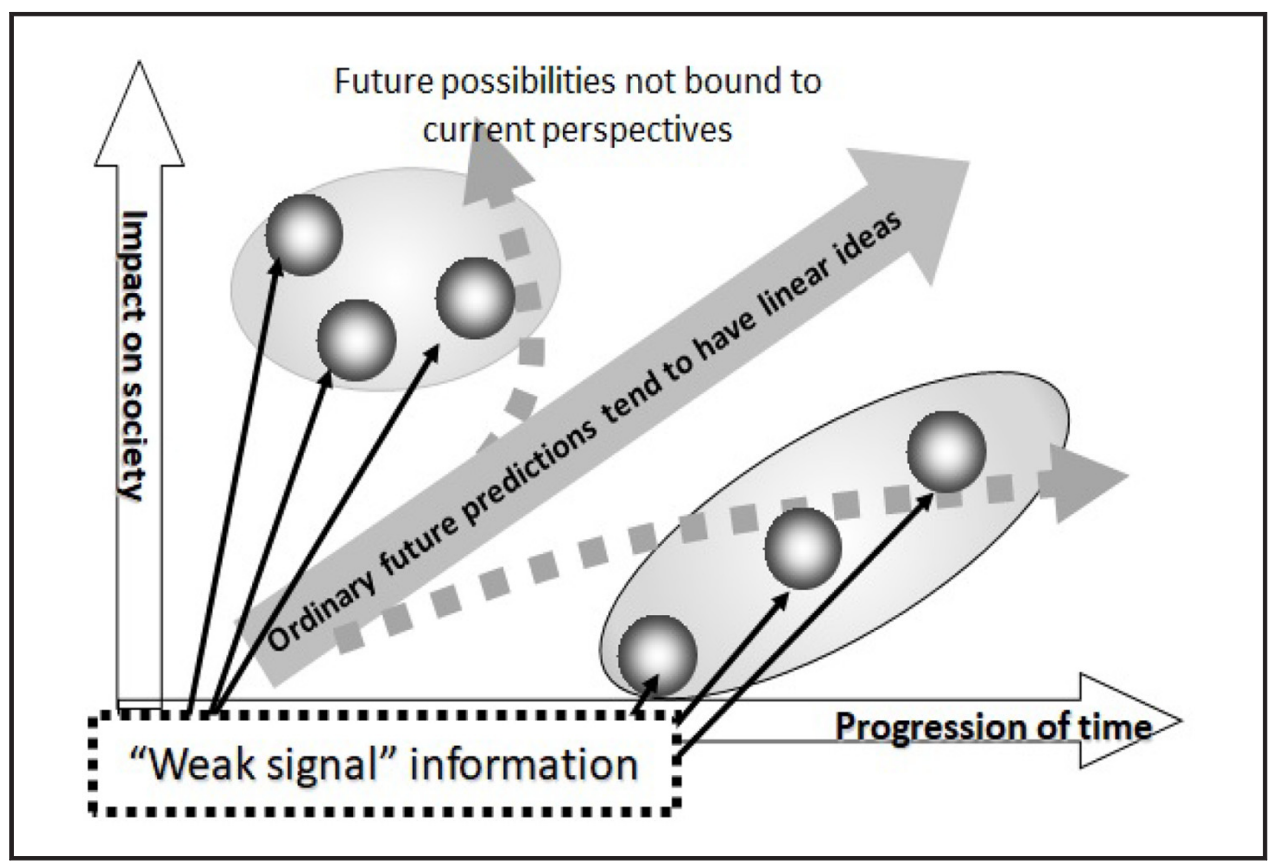

\begin{tabular}{l|l|l} 
VOL. 23 NO. 12021 & FORESIGHT & PAGE 19
\end{tabular} 
the history of the development of horizon scanning, the previously-mentioned scenario planning method also was a derivative method that was developed and has come to be frequently used in practice. Foresight, which combines horizon scanning and scenario planning, has been researched and developed into a variety of patterns around the world and a methodology similar to the method that Saritas (2015) systematized has become commonly used in Japan. His team invited future experts to explore, through big-picture research, future trends, drivers, wildcards, discontinuities and weak signals that could shape the future as foresight activities (Saritas and Smith, 2011).

Since the advent of the $21^{\text {st }}$ century, foresight has been practiced as part of national innovation systems (NIS) (Freeman, 1995) at the national level in a variety of countries. Georghiou (2007) reported that foresight activities have been conducted in conjunction with NIS in the USA, Canada, UK, Germany, The Netherlands, Austria, Russia, Australia, New Zealand, Columbia, India, South Korea, Kazakhstan, Taiwan, Malaysia, Egypt, Morocco, South Africa and other countries. In Germany, the Fraunhofer Society has taken the lead in progressively applying foresight not only in NIS but also in the preparation of strategic scenarios at the corporate level (Cuhls, 2015).

Amanatidou et al. (2012) stated that there are two different scanning method approaches, exploratory and issue-centered and that the choice of the best scanning method depends on context and content.

On the other hand, transnational foresight activities have been actively conducted in European countries. The European Union also has explored a variety of foresight methodologies including horizon scanning (Cuhils et al., 2015; European Commission/ European Union, 2018).

In Japan as well, the National Institute of Science and Technology Policy (NISTEP), which is under the auspices of the Ministry of Education, Culture, Sports, Science and Technology, has started conducting activities using horizon scanning (Science and Technology Foresight Center, 2015) and the Japan Science and Technology Agency's (JST) Center for Research and Development Strategy has been using it on a trial basis (Takahashi et al., 2019).

Recently, the horizon scanning method has been used as a component of risk prioritization in evidence-based policymaking Garnett et al., 2016. Horizon scanning is inherently suitable for this purpose because it focuses on social changes, not merely technological advancements.

In this way, horizontal scanning has become one of the most popular methods of foresight, mainly in Europe, and much research has been done on its use as a practical policy-making method. However, no comprehensive studies have previously been conducted comparing a variety of foresight methods from the viewpoint of predictive value (Figure 1).

\section{Example of weak signals in 2014 regarding COVID-19}

In November 2014, by using the horizon scanning method, one of the authors himself collected four weak signals; danger of infected mosquitos, epidemic of syphilis among homosexuals, prostitution and drug prevalence in EU countries and tuberculosis epidemic in Japanese slums. They strongly implied a potential but significant danger from a widespread pandemic disease and an urgent need for national epidemic prevention policy. On the other hand, he simultaneously collected another four weak signals regarding China, namely, Chinese Navy military action near Vietnam, fierce gross domestic product (GDP) competition between the USA, China and Japan, the widespread use of Chinese language in compulsory education, and 
departure of Japanese companies from business in China. They apparently implied that a trial period would occur in the near future to see if China could become a world leader. Those two significant implications seemed to be both non-linear and independent social changes at that time. He found those eight weak signals from his institute's horizon scanning database, which collects many such unusual weak signals daily. A record remains of his proposal of those two implications at a foresight workshop held at a university in Tokyo on November 28th, 2014. It is unfortunate that few people at the workshop with the exception of him had no special interest in those two implications.

Five years later, the COVID-19 pandemic disease emerged, during which global pandemic prevention policies have come to be the most important in every country, and where China happened to take on an important role as the country in which the disease originated. It is true that the author's foresight activity with the horizon scanning method surprisingly foresaw clearly events that would take place five years later. Even though each weak signal did not describe an exact incident at the point of 2019, he was able to formulate predictive implications based on such weak signals. This case is a coherent example of how a series of discussions on the prediction value of foresight scenarios can be significant to a certain extent.

\section{Hypotheses of predictive value to compare scenario methods}

In conventional forecasting, it is often the case that scenarios are created using the technology roadmap or another well-known method that first identifies technologies, which would be desirable to penetrate in the near future, and then looks at what sort of society needs to be created to realize the dissemination of such technologies. Some practical case studies have been found where this technique has been described as "backcasting" as contrasted with "forecasting" in the sense that first a desirable future technology, not society, is defined and then works backward to set current goals. However, this is clearly a misconception of the process. The reason is that the technique is the same as conventional forecasting at the point where the desired technology is set. Properly speaking, backcasting requires that scenarios be created by first looking ahead at what sort of changes society might undergo and then what sort of technologies are required in that society (Dreborg, 1996; Robinson, 2003).

It is easy to embody this essence of backcasting in foresight with the use of horizon scanning. The reason is that a major feature of the horizon scanning is that it is based on numerous weak signals and first excludes the most probable observations about technology dissemination when considering what sort of changes may take place in society. To mitigate the oversensitivity of policymakers and scientists about the predictive value of forecasts and scenarios, it is necessary to prove that social change scenarios originally prepared for such backcasting can be expected to have a higher predictive value than scenarios based on the assumption of technology dissemination (Mattila and Riina, 2011).

This study makes the following hypotheses.

H1: Scenarios prepared using horizon scanning can be expected to have a higher predictive value than scenarios prepared using conventional forecasting methods.

In addition, the significance of the use of the scenario method is greater for social change scenarios that are not extensions of the status quo, but entail explicit changes. No matter how high the predictive value is, if that future is an extension of the status quo, then it is sufficient to think of a future based on the probability of the status quo, so it is not really necessary to go to the trouble of using the scenario method. Accordingly, the following hypothesis has been made about this point. 
H2: Scenarios prepared using horizon scanning are able to depict significant changes better than scenarios prepared with conventional forecasting methods.

If the significance of horizon scanning is validated regarding these two hypotheses, then its value regarding scenario methods will also rise.

In validating $H 1$, what sort of methods are we able to use to measure the predictive value of social change, including that of industries and businesses? Social change has been part of history, so fact-finding methods used in the study of history are informative. In research on economic history and history since modernization, qualitative fact-finding methods have mainly been used that are based upon narrative studies, contextual analyzes or historiography as relates to statesmen and prominent figures (Franzosi, 1998; Best and Schröder, 2006). However, over the past 50 years, there has alternately been a focus on historical fact-finding methods that are based upon the use of quantitative data for verification (Furet, 1971). Although there is still much debate about these two methods (Carus and Ogilvie,2009), the quantitative method is believed to be more effective in terms of evidence for today's policymakers and scientists. In addition, in the relationship between experts and the public as concerns science, prior research has validated that the public understanding of science model, which is based upon two-way communication, has been more practical than the public acceptance model, which is based upon the one-way provision of knowledge by experts (Bucchi and Neresini, 2002). Research has also been conducted on the importance of the public sphere as a domain bringing together policymakers and scientists (Edwards, 1999, p. 144). In cases where matters relating to social change are considered, the core structure is the public sphere and the most powerful stakeholders are not engineers or inventors, but ordinary people. This importance is given to ordinary people, as explained previously, also coincides with the fact that the rate of diffusion is more important for modern policymakers and scientists than the rate of implementation. Accordingly, in this study, we have defined this as the predictive value of a scenario as measured by quantitative surveys of ordinary people.

\section{Study design}

To verify these four hypotheses, an online survey was conducted of ordinary people's attitudes. On May 13, 2019, online questionnaires were sent to 1,135 men and women between the ages of 20 and 69 residing in Japan, and valid responses were received from 262 (response rate: $23.1 \%$ ). The responses were collected so that the number would be uniform between men and women, as well as for each 10-year age interval.

The questionnaires presented 20 scenarios about future society, as shown in Tables 1-4. In addition, the respondents were to rank their answers according to a five-point Likert scale for each question: "do you think the scenario is accurate?" and "do you think that Japanese society has significantly changed?" The first question measures the predictive value of $\mathrm{H1}$ and the second seeks to validate

\section{H2: The actual questions were written as given below.}

Each of the scenarios listed below is a 'scenario about Japanese society in the near future' that was prepared by a meeting of experts in 20XX. In other words, these scenarios are descriptions that envision Japanese society in the future as viewed from the year 20XX. Please share your opinion about the extent to which these scenarios have become reality today in the year 2019 .

Here, "20XX" indicates the actual year when each of "future society scenario" was prepared as shown in Tables $1-4$.

Scenarios A1 through A8, shown in Table 1, are taken from synopses created for "future society scenarios" that the JST Research Institute of Science and Technology for Society prepared using horizon scanning (Washida et al., 2009). 
Group A scenarios prepared by the Japan

Science and Technology Agency's (JST)

Research Institute of Science and Technology

for Society (RISTEX) using horizon scanning in 2006 (eight scenarios)

Scenario A1: Japan sinks because of people, education and human resource problems

\section{Scenario A2: various kinds of polarization}

Scenario A3: heat conscious society predicated on diet

Scenario A4: pursuit of Japan's uniqueness
In the Japan of 2019, as a result of the significant advancement of globalization, it will be common for people to use multiple languages in their daily lives. In addition, the Japanese government will have alleviated the decrease in the working population, which has resulted from a decline in the overall population, fewer births and an aging society, by relaxing restrictions on accepting immigrants. On the other hand, this greater globalized awareness will have created a contrary phenomenon where there is a regular outflow of many talented Japanese to other countries. This change has highlighted the insufficiencies and defects present in those trained to support Japan's science and technology and the educational system. The acceptance of immigrants has allowed many foreigners to move into occupations where they play key roles in society and a significant percentage of the people conducting research and studying at universities and research institutions is also occupied by foreigners

To address this situation, leading companies and universities will take it upon themselves to selectively establish educational and research institutions for developing people capable of exercising strong leadership, significantly unsettling equality of education in Japan

As Japanese society ages further, this will have led to a significant increase in the elderly seeking to once again receive an advanced education after retirement, and a new sort of education will also start to take shape where these elderly people pass on to younger generations the skills and wisdom that they accumulated Japanese society in the year 2019 will have become increasingly polarized in a variety of ways. First, the income gap will have widened and the general sentiment among the populace identifying itself as middle-class will have completely become a thing of the past. Also, there will be a sharp generational polarization between the elderly seeking to preserve traditional Japanese values and the young articulating values within the context of the global society. Within this sort of polarized living environment, a great divide in socially-accepted ideas will have emerged between the segment pursuing a high quality of life and actually being able to realize it and those who think that, even so, one should live efficiently and practically Health maintenance and management will have become a major common interest for Japanese people in the year 2019. There will have developed a particularly strong awareness about leading a health-conscious life by improving and planning one's diet. At the same time, advances in human genome research will have led to a plethora of services helping each and every person to easily and thoroughly comprehend his or her own physical makeup. As a result, advances will have been made in ways to abate lifestyle diseases, further extending the average lifespan. Presupposing that people will live such a long life, the stereotypical life plan in which people build a home in their $30 \mathrm{~s}$ and $40 \mathrm{~s}$ and then retire in their $60 \mathrm{~s}$ will begin to have lost its relevance, and a greater emphasis will be placed on "variable" life planning as it applies to each specific individual In the year 2019, when Japanese automobile companies and electronics are leading the world and Japanese food and entertainment culture is popular worldwide, "Japaneseness" in global society will have significantly changed from the conventional images of Mt. Fuji, samurai, sumo and geisha, to one that is represented by values expressed in the keywords: compact, ultra-high tech, highperformance and minimalism

Under such circumstances, Japan will have developed firm values about maintaining a strong national consciousness that desires to lead the world, particularly, as the nation has done in science and technology, and the importance of a globally-conscious Japan to search for and realize its uniqueness. A value will have taken root among many people and engineers so that they ask the question "does this convey Japaneseness?" about any product or service, leading to the formation of a new patriotism 
Table 1

Scenario A5: unanticipated rash of advanced intellectual crimes

Scenario A6: autonomous societies

Scenario A7: establishment of autonomy in online societies

Scenario A8: emergency of lifestyle emphasizing a second life
Due to a negative synergistic effect brought about by more widespread use of advanced IT services and a rapid increase in other people's settling in Japan, the Japan of 2019 has been experiencing an increase in advanced intellectual crimes, which had never been anticipated before. At the same time, the impact of increasingly complex international politics and infiltration of international terrorists into Japan along with other factors have become another factor in the decline in public security. The misuse of science and technology is prominent in these types of intellectual crimes. There has not just been a rapid increase in the improper use of IT services but also the abuse of biological and health data, as well as privacy violations and other such crimes. Because Japanese society has aged and the gap between the haves and the have-nots has broadened further, there are greater segments of society that are more easily targeted in these sorts of intellectual crimes

In 2019, Japan will have done away with its traditional basic policy for local administration and sought to be a society transitioning toward consolidation of the present regional administrative structure of prefectures, cities, towns and villages into larger administrative units where each independent community within a region is self-reliant (autonomous). The principle of universal service, which had previously been maintained, will have already become impossible to sustain. Accordingly, based on the philosophy of large administrative units and compact self-government, the concept of cities, communities or organizations maintaining their own rights and lives according to their particular methods and rules will have gradually become more pervasive. In conjunction with this, there will have also emerged municipalities that do not depend at all on administrative authorities for urban infrastructure, welfare programs and other such social services and have sought to create these on their own in an effort to be independent and selfsupporting. At the same time, communities of foreigners, which have increased in Japan, will also align themselves with this movement and signs will have appeared indicating that Japan is transforming into a society of collectives of diverse communities that also embrace ethnic issues

Although the digital network society represented by the spread of the internet had been one where "connecting" was regarded as an absolute value, in the year 2019, the information network society, which had developed in a dramatic fashion, has begun to create an environment where the necessity of "taking the bold step of not connecting" is touted. Because communication technology had gone on to develop beyond our natural senses, it has become critically important that people deliberately protect themselves in online society. Up until now, there had been much contrast between the real and the virtual. The virtual world has already been taken for granted, and there has been a greater focus in the virtual world on the importance of returning to humanity, as well as independence and self-reliance Extension of the average lifespan brought on account of progress made in medical science has increased the number of people who wish to live a full life after retirement. In the year 2019, baby boomers, already past the age of 70 , are active consumers showing no sign of declining at all and are engaged in activities enabling them to participate in society and hobbies, which they were unable to pursue when working. These older baby boomers are now the mainstay of Japan's dynamism. New service industries targeting this market have also developed, and a greater portion of the elderly segment enjoy consumption disproportionate to their age. Seeing how this baby boomer generation lives, younger generations also have reassessed their life plans, and there are more people seeking to have the balance of their lives focused on activities after retirement rather than during their work life

Scenarios B1 through B3, shown in Table 2, are cited from scenarios that the New Energy and Industrial Technology Development Organization (NEDO, 2007) prepared based upon the "technology strategy map" (Ministry of Economy, Trade, and Industry [METI], 2006), which the Ministry of Economy, Trade and Industry of Japan drew up and released publicly through its website, envisioning Japanese society around the year 2025. The NEDO scenarios were divided into 24 sections, a large number, which made it impossible for all of them to be included in the questionnaire and shown to people. So, it was decided to use a simple scaled-down pamphlet 


\section{Table 2 Group B scenarios about future society}

Group B excerpts representing a social change in the scenarios prepared in 2007 by the New Energy and Industrial Technology Development Organization (NEDO) using a conventional forecasting method (three scenarios)

Scenario B1: combinations of various transportation means

Scenario B2: development of massive architectural structures in large cities
The age will have come to an end in which people depend on personal vehicles and public trains or buses when moving around in or between cities such as during commuting. Methods will have become commonplace for many people where they commute by using a car sharing service from their home to the closest train station, then drop off the car at the station and get on a train (park and ride)

Tokyo, Osaka and other large cities in Japan will be lined with skyscrapers over $1,000 \mathrm{~m}$ high (300 floors), covering the sky. The work of constructing these structures will be performed by intelligent robots, which will build these high-rises safely, securely and quickly. Plant factories will be created inside these high-rise buildings and on their walls, significantly contributing to controlling heat island phenomenon and carbon dioxide emissions

On street corners in Japan, many police robots and information robots, as well as other robots will be working. These robots will be operating automobiles, pushing wheelchairs and performing other such activities. Town planning will have been realized that provides universal services

along with beautiful illustrations, which NEDO prepared in 2007 with the general public in mind and were originally based upon a 2006 (NEDO, 2007). NEDO published five pamphlets. Their titles were No.1; energy and life, No.2; cities and transportation infrastructure, No.3; information technology and ubiquitous, No.4; factories and manufactures and No.5; biotechnology and medical services. The contents of the pamphlets No.1, No.3, No.4 and No.5 looked too futuristic, therefore, we determined that they were not suitable to be compared with other scenarios in this study. The pamphlet No.2 presents five scenarios from sections on cities and infrastructure, but one of these had already been realized and widely diffused on Google maps and other uses by the year 2007 when presented, so we determined that it was not suitable for this study. In addition, another scenario in it concerned automobiles using hydrogen for fuel, but hydrogenfueled vehicles have only been achieved worldwide by Toyota. So, there was a risk that respondents might misunderstand this as the strategy of a specific company. We, therefore, determined that it was unsuitable for this study. The remaining three scenarios all suggested major technological developments, which appeared to also have a significant effect on social change, so we determined that they would be very appropriate for the purposes of this study. As mentioned earlier, these three scenarios were created using the technology roadmap method, so their principal objective is not a future prediction, but rather to present a vision of technology that might develop. Nevertheless, NEDO also concurrently gave accounts of social changes, accompanied by beautiful illustrations, for cases where such technology diffused. Although the method that NEDO used for describing society appeared to be an example of misguided backcasting as described previously, it was able to at least extend beyond a mere vision of technology to be appreciated as a social prediction. For this study, only the portion pertaining to social change was extracted and included in the questionnaire. Although consideration was given to having the technology prediction scenarios that NISTEP prepared based upon the Delphi method (Udagawa and hanzato, 2001) serve as alternates to these NEDO scenarios if more content were added, there were no descriptions of social changes for the general public as the focus is on the rate of implementation as mentioned previously. In addition, in 2001, NISTEP published technology prediction scenarios that used 2030 as the target year, so it was determined that the time wavelength for prediction was too long, and thus, not suitable for this study.

Scenarios C1 through C6, shown in Table 3, are future scenarios that eight Hitotsubashi University Graduate School of Business Administration students prepared using horizon scanning as part of a graduate class in 2012. Although not 
Group C scenarios prepared using horizon scanning by graduate students (six students) in the Hitotsubashi University Graduate School of business administration in 2012

Scenario C1: coordination will move ahead toward forming an Asian economic community

Scenario C2: polarization of the view toward life and death by people in a society of longevity

Scenario C3: increasing globalization will conversely increase nationalism

Scenario C4: time will come when energy is extracted from everything

Scenario C5: change in work lifestyle (focus on women, the elderly and robots)

Scenario C6: everything will be made-to-order

ASEAN, China, Japan, Korea and Taiwan will participate in the formation of a framework for economic cooperation in Asia that is similar to the EU and will also have a significant impact on the global economy. Lively discussions will take place at summit meetings as nations attempt to abolish customs duties, use a common currency and engage in other forms of collaboration

With the evolution of medical technology, a longevity society will have arrived where people live longer than they ever have. Within that context, there will be greater polarization between people who desire to live as long as possible using any possible means and people who wish to die naturally without unduly extending their lives. Debate will have begun on permitting death with dignity from the standpoints of the rapid increase in medical costs and maintaining quality of life

As a result of greater globalization and interconnectedness among the economies of countries around the world, countries will conversely see a rise in nationalism desiring to prioritize their own interests. More countries will restrict immigrants and levy tariffs

The shutdown of nuclear power plants will have focused attention on renewable energies. Technologies will have emerged that extract energy from sunlight, wind, geothermal, biomass and almost anything else, leading to a lifestyle that aspires for electricity self-sufficiency

As Japan's population decreases with fewer children and the elderly accounting for a greater proportion of the population, labor shortages will occur and attention will be turned toward strengthening the labor force with the help of women, the elderly and robots to make up for this shortage. The previous practice where men were at the core of the workforce with lifetime employment and the seniority system will collapse

The popularization and pervasive use of three-dimensional printers and online shopping will turn into everything being customized to one's own preferences and made-to-order. Factories will produce products after they receive individual orders

previously published, they were used in this survey with the permission of the faculty and students.

Scenarios D1 through D3, shown in Table 4, are three main scenarios cited from future scenarios depicting the health care field that the Deloitte Centre for Health Solutions (2014) prepared and released to the general public through its website, envisioning a global society in the year 2020. This document also lists a great number of scenarios, and it was impossible to present all of them on the questionnaire. However, as the content of many of these scenarios was very similar, we decided, for the sake of consistency, to extract only the portions relating to social change in the first three scenarios and include them on the questionnaire. This process was not arbitrary.

While scenarios of Group A (indicated as HS2006 in Tables 5 and 6) and Group C (indicated as HS2012 in Tables 5 and 6) were prepared using horizon scanning, those of Group B (indicated as NEDO 2007 in Tables 5 and 6) and Group D (indicated as Del2014 in Tables 5 and 6) were prepared using other techniques. The most important perspective of this study is the comparison of results obtained from the different methods. 
Group D excerpts representing common social change, which serve as the setting, that are taken from among the 10 future scenarios depicted in the "health care and life sciences predictions," which the Deloitte Center for Health Solutions seems to have prepared using a conventional forecasting method in 2014 (three scenarios)

Scenario D1: new relations between patients and health care systems in the net era

Scenario D2: remote medical care

Scenario D3: wearable medical devices penetrated
Health care organizations now engaged with patients though social media, regularly gauging their needs and driving them to appropriate products and services for their budget and health-care requirements. Online patient communities have grown exponentially and are rich sources of crowd-sourced data, with rating systems for drugs and health-care proposition. Advanced analytics on patient chatter in these communities gather health information, providing a better understanding of which treatments deliver the best outcomes, allowing real time tailoring of pharmaceutical messages and services. They also provide early alerts on diseases, such as influenza. Business and governments work with communities of patients, hospitals and payers to identify best practices and cost-effective treatments. New provider and industry models, including mutual and other forms of collaboration and cooperation, help decrease co ts and improve care. Consumers accept that they are largely responsible for their health - incentives for good behavior and now firmly established - from reductions in co-payments to lower taxes (for example, for not smoking). Privacy and security of data remain concerns, but there is an understanding of the benefits of sharing data. Payers and providers embrace complex patients, having invested in analytics and programs that lead to new care pathways. Clinicians go from being reluctant to engage with electronic health information from wearables to active engagement in developing and improving the technology. Most patients in developed countries now have access to their own electronic health records, and decide who to share it with

Web-based portals that enable regulatory compliment (and reimbursable) videos interactions between patient and clinician are now supported by a wide array of web-integrated wireless monitoring devices. Health care productivity has been revolutionized including reducing traveling and waiting times, and inconvenience by providing routine contacts through telemedicine-enabled clinical e-visits, supported by digital diagnostic tools, which facilitate physical examinations at a distance. Robotic or robotically enhanced surgery is commonplace, using robotically enhanced surgery platforms to access detailed radiological information while allowing the surgeon enhanced visualization of the surgery with his/ her three-dimensional goggles. The silos between hospital and community care have been reduced by designing care pathways around the patient, with hospital doctors and nurses running clinics and delivering care in the community and primary care staff providing in-reach services to community and specialist hospitals

The tipping point for broad adoption of wearables has been reached - wearables are used voluntarily and are recommended as part of prevention and wellness protocols. While privacy is still a concern, effective regulation and corporate branding have made consumers more willing to share their device data

\section{Survey results}

Table 5 shows the results for the two questions as concerns all of the 20 scenarios that were included in the questionnaire. It shows the mean for the total percentage of respondents who replied "I agree" or "I agree somewhat" to questions about "predictive value" and "significant change" relating to social change scenarios prepared using each of the method. Although several scenarios in Groups A and C indicated a very high predictive value, the other scenarios in these groups had low predictive value. The significant scattering in these two groups caused a relatively 


\section{Table 5 Results for the two questions of 20 scenarios: \%}

\begin{tabular}{|c|c|c|c|}
\hline Group & Scenario & $\begin{array}{l}\text { This scenario is accurate } \\
\text { Total \% of I agree and I agree somewhat }\end{array}$ & $\begin{array}{c}\text { Japanese society has significantly changed } \\
\text { Total \% of I agree and I agree somewhat }\end{array}$ \\
\hline Group A (HS2006) & $\begin{array}{l}\text { A1 } \\
\text { A2 } \\
\text { A3 } \\
\text { A4 } \\
\text { A5 } \\
\text { A6 } \\
\text { A7 } \\
\text { A8 } \\
\text { Mean of Group A }\end{array}$ & $\begin{array}{l}31.7 \\
49.6 \\
50.7 \\
22.9 \\
58.4 \\
21.8 \\
42.7 \\
44.2 \\
40.3\end{array}$ & $\begin{array}{l}59.9 \\
52.3 \\
55.3 \\
34.0 \\
63.0 \\
26.7 \\
49.6 \\
51.1 \\
49.0\end{array}$ \\
\hline Group B (NEDO 2007) & $\begin{array}{l}\text { B1 } \\
\text { B2 } \\
\text { B3 } \\
\text { Mean of Group B }\end{array}$ & $\begin{array}{l}24.1 \\
20.6 \\
27.4 \\
24.0\end{array}$ & $\begin{array}{l}39.7 \\
34.7 \\
40.8 \\
38.4\end{array}$ \\
\hline Group C (HS2012) & $\begin{array}{l}\text { C1 } \\
\text { C2 } \\
\text { C3 } \\
\text { C4 } \\
\text { C5 } \\
\text { C6 } \\
\text { Mean of Group C }\end{array}$ & $\begin{array}{l}22.5 \\
47.3 \\
54.9 \\
53.0 \\
56.5 \\
21.7 \\
42.7\end{array}$ & $\begin{array}{l}30.6 \\
43.2 \\
46.2 \\
50.8 \\
58.8 \\
34.0 \\
43.9\end{array}$ \\
\hline Group D (Del2014) & $\begin{array}{l}\text { D1 } \\
\text { D2 } \\
\text { D3 } \\
\text { Mean of Group D }\end{array}$ & $\begin{array}{l}29.0 \\
33.9 \\
29.4 \\
30.8\end{array}$ & $\begin{array}{l}39.3 \\
42.0 \\
41.6 \\
41.0\end{array}$ \\
\hline
\end{tabular}

Table 6 Results for the two hypotheses (comparison of mean values)

\begin{tabular}{|c|c|c|c|c|c|c|c|c|c|c|}
\hline \multirow[b]{2}{*}{ Hypotheses } & \multicolumn{2}{|c|}{ Group A HS2006 } & \multicolumn{2}{|c|}{ Group B NEDO 2007} & \multicolumn{2}{|c|}{ Group C HS2012 } & \multicolumn{2}{|c|}{ Group D Del2014 } & \multicolumn{2}{|c|}{ Average } \\
\hline & $M$ & $S D$ & M & $S D$ & $M$ & $S D$ & M & $S D$ & $M$ & $S D$ \\
\hline $\begin{array}{l}\text { "This scenario is accurate." (H1: } \\
\text { predictive value) } \\
\text { "Japanese society has significantly }\end{array}$ & $40.3^{* *}$ & 12.6 & $24.0^{* *}$ & 2.8 & $42.7^{* *}$ & 14.8 & $30.8^{* *}$ & 2.2 & 34.4 & 13.3 \\
\hline changed" (H2: degree of change) & $49.0^{* *}$ & 11.7 & $38.4^{* *}$ & 2.7 & $43.9^{* *}$ & 9.6 & $41.0^{* *}$ & 1.2 & 43.1 & 9.9 \\
\hline Note: Note: ${ }^{* \star} p<0.01$ & & & & & & & & & & \\
\hline
\end{tabular}

large standard deviation. No such significant scattering was seen in either Groups B or D. Based upon these results, we may state that, although horizon scanning also clearly has outliers, the method is able to create several truly accurate future scenarios. By contrast, Groups B and D had low predictive value overall, so the standard deviation was also relatively small.

As mentioned earlier, the core issue of this study is to compare foresight methods. Each of the four groups includes a different number of scenarios, so the comparison ought not to be made among the 20 scenarios, but rather among the mean values of the four groups. Table 6 shows a comparison of the group mean values.

The survey results show that for $\mathrm{H} 1$ (predictive value), the predictive value of scenarios prepared using horizon scanning was $40.3 \%$ for Scenario Group A and $42.7 \%$ for Scenario Group C. By contrast, for scenarios prepared using conventional forecasting methods, the 


\section{Table 7. Scenario creation process}

Groups A and C horizon scanning

\begin{tabular}{|c|c|c|c|}
\hline Processes & $\begin{array}{l}\text { Groups A and C horizon scanning } \\
\text { method }\end{array}$ & Group B & Group D \\
\hline Inputs: data bias & $\begin{array}{l}\text { Little bias } \\
\text { Inputs comprising numerous "weak } \\
\text { signals" }\end{array}$ & $\begin{array}{l}\text { Bias present } \\
\text { Mainly technical fields }\end{array}$ & $\begin{array}{l}\text { Bias present } \\
\text { Mainly life science and health } \\
\text { care industries }\end{array}$ \\
\hline $\begin{array}{l}\text { Throughputs: } \\
\text { perspective bias }\end{array}$ & $\begin{array}{l}\text { Bias eliminated that is particular to } \\
\text { experts } \\
\text { Guidance also given to researchers } \\
\text { so that they regard themselves as } \\
\text { "one person in society" }\end{array}$ & $\begin{array}{l}\text { Bias of desired observations } \\
\text { relating to dissemination of } \\
\text { technology } \\
\text { Results from setting an objective } \\
\text { of "asking for understanding of } \\
\text { R\&D investment" }\end{array}$ & $\begin{array}{l}\text { Factors causing bias in } \\
\text { perspective and interpretation not } \\
\text { found }\end{array}$ \\
\hline $\begin{array}{l}\text { Outputs: height of } \\
\text { layers and breadth } \\
\text { of field }\end{array}$ & Layers of "society" & $\begin{array}{l}\text { After layers of "technology" are } \\
\text { depicted, social change is } \\
\text { misleadedly backcasted }\end{array}$ & Layers of "industry and business" \\
\hline
\end{tabular}

predictive value was $24.9 \%$ for Scenario Group B and 30.8\% for Scenario Group D. The comparison of the overall mean for each of the groups resulted in the finding of a significant difference (1\%) with student's $T$ test. These results may be said to support $H 1$.

In addition, compared to results of $49.0 \%$ for Scenario Group A and $43.9 \%$ for Scenario Group C as relates to $\mathrm{H} 2$ (degree of change), the results were $38.4 \%$ for Scenario Group B and $41.0 \%$ for Scenario Group D, all of which were low values. Comparison of the overall mean for each of the groups resulted in the finding of a significant change (1\%) with student's $T$ test. Accordingly, it may be said that $H 2$ was also supported.

\section{Analysis, implications and conclusion}

As shown in Table 7, the scenario preparation was broken down into three processes, namely, inputs, throughputs and outputs. $\mathrm{H} 1$ and $\mathrm{H}_{2}$ were analyzed and examined in order based on the perspective of how differences in each process affected survey results.

\subsection{Analysis of hypotheses 1 (predictive value)}

Scenarios prepared using horizon scanning were assessed "to have been accurate" to a higher degree than other scenarios. This is believed to be attributable to inputs (lack of bias in the data) and throughputs (lack of bias in perspectives) in the process of preparing social change scenarios.

When comparing inputs, it is surmised that Scenario Group B comprised mainly information in technical fields and Scenario Group D mainly information in the life science and health care industries in contrast to horizon scanning where numerous weak signals are input. Nevertheless, in the cases of Groups B and D, it is difficult to consider changes in people's values and lifestyles or other social changes. It is believed that the lack of information about changes outside the field targeted for prediction lowered the predictive value of future scenarios about that area.

In addition, when comparing throughputs, a look at the process of formulating the technology strategy map 2006, upon which Scenario Group B is based, and the objectives, shows that its purpose is to:

explain to the general public and seek their understanding about the approach, content, products, and other aspects relating to R\&D investments that the Ministry of Economy, Trade and Industry of Japan has made 
and to prepare a proposal for a task force in which:

universities, private companies (manufacturers of products, components, materials, devices and other items), the Ministry of Economy, Trade and Industry of Japan (bureaus and sections responsible for overseeing each field as well as the Industrial Science and Technology Policy and Environment Bureau), NEDO, the National Institute of Advanced Industrial Science and Technology, and other organizations participate

In other words, it was expected that the technology strategy map would provide accountability for the probability of research and development investment in the technology selected by the Ministry of Economy, Trade and Industry of Japan. It is believed that this produced a bias in desired observations about the dissemination of technology. While with the horizon scanning method, guidance is provided, in particular, for Scenario Group A and Scenario Group C so that, although researchers are participating members, they are instructed "to consider themselves as just one member of society" within the context of all the people in society. It is believed that this instruction was successful in eliminating the bias characteristic of experts.

Based on the above, the high rate of accuracy of the predictions produced with the horizon scanning method is thought to be attributable to the lack of bias in input data and the lack of bias in perspectives in throughputs (elimination of bias particular to experts).

\subsection{Analysis of hypotheses 2 (significant change)}

Scenarios prepared using horizon scanning were assessed to address "significant changes for Japanese society" to a greater degree than other scenarios. This is believed to be attributable to the anticipated output area (height of layers and breadth of field).

The horizon scanning method assumes that changes in "society" corresponding to those outside specific science and technology fields or outside industry and business are important output areas. Accordingly, the delineated future scenario is basically understood to be a major social change trend. While Scenario Group B first draws a roadmap of the layers of "technology" and from there changes to "society" are worked out backward. If one considers that there will be some "major changes for Japanese society" that originate in technology changes, then it is believed that Scenario Group B, for which technology layers are set as output areas and societal changes derived that originate in changes in technology, is sufficiently likely to miss "major changes for Japanese society" to a greater extent than the horizon scanning method.

Because the final outputs of Scenario Group D are layers of industry and business in the first place, it is natural that "major changes for Japanese society" are subordinated.

These analyzes were conducted of each hypothesis, which made the following two implications regarding elements of the scenario review process and characteristics of the derived scenarios.

Implication 1: By eliminating bias in input data and perspectives adopted when considering scenarios, it may be expected that scenarios will be derived that have even higher "predictive value."

Implication 2: By setting the layers of anticipated outputs high and the fields broad, it may be expected that scenarios will be derived that have even greater "change."

In total, future scenarios created by the horizon scanning method can be expected higher predictive values than those by other conventional methods.

\section{Limitations and future research}

This study has, however, several limitations. First, the size of the study was not that large. If the study were conducted using an even bigger sample size, then more accurate results would 
have likely been obtained. Also, not so many past scenarios were presented. If scenarios, which had been prepared using more diverse techniques, were similarly validated by a survey, then more findings would likely have been obtained. Moreover, the debate over the definition of predictive value has yet to be resolved. The definition of predictive value in this study is quantitative and the diffusion rate was also taken into consideration, so we believe that it is pertinent to the core interests of modern policymakers and scientists. However, it is a method that differs from the rate of implementation in conventional technology prediction, so there should be discussed to form on even greater consensus on this matter. Nevertheless, even considering such limitations, the high rate for the predictive value of the horizon scanning method validated in this study is significant. It is hoped that attempts will also be made to verify more scenarios that have previously been prepared using horizon scanning methodology.

\section{References}

Aguilar, F.J. (1967), Scanning the Business Environment, Macmillan, London.

Amanatidou, E., Butter, M., Carabias, V., Könnölä, T., Leis, M., Saritas, O., Schaper-Rinkel, P. and van Rij, V. (2012), "On concepts and methods in horizon scanning: lessons from initiating policy dialogues on emerging issues", Science and Public Policy, Vol. 39 No. 2, pp. 208-221.

Best, H. and Schröder, W.H. (2006), "Quantitative historical social research. The German experience (1987)", Historical Social Research/Historische Sozialforschung. Supplement, No. 18, pp. 120-135.

Bucchi, M. and Neresini, F. (2002), "Biotech remains unloved by the more informed", Nature, Vol. 416 No. 6878, pp. 261-261.

Carus, A.W. and Ogilvie, S. (2009), "Turning qualitative into quantitative evidence: a well-used method made explicit 1", The Economic History Review, Vol. 62 No. 4, pp. 893-925.

Cuhls, K. (2015), "Foresight in Germany: implications for policy making", in D. Meissner et al. (Ed.) Science, Technology, and Innovation Policy for the Future, Springer, Heidelberg New York, NY Dordrecht, pp. 199-217.

Cuhls, K., Van der Giessen, A. and Toivanen, H. (2015), Models of Horizon Scanning. How to Integrate Horizon Scanning into European Research and Innovation Policies, Brussels: Report to the European Commission (end report of the European Commission, A 6, Study on Horizon Scanning).

Dreborg, K.H. (1996), “Essence of backcasting”, Futures, Vol. 28 No. 9, pp. 813-828.

Edwards, A. (1999), "Scientific expertise and policy-making: the intermediary role of the public sphere", Science and Public Policy, Vol. 26 No. 3, pp. 163-170

European Commission/European Union (2018), Transitions at the Horizon: Perspectives for the European Union's Future Research- and Innovation-Related Policies, Brussels.

Franzosi, R. (1998), "Narrative as data: linguistic and statistical tools for the quantitative study of historical events", International Review of Social History, Vol. 43 No. S6, pp. 81-104.

Freeman, C. (1995), "The national system of innovation in historical perspective", Cambridge Journal of Economics, No. 19, pp. 5-24.

Furet, F. (1971), "Quantitative history", Daedalus, pp. 151-167.

Garnett, K., Lickorish, F.A., Rocks, S.A., Prpich, G., Rathe, A.A. and Pollard, S.J.T. (2016), "Integrating horizon scanning and strategic risk prioritisation using a weight of evidence framework to inform policy decisions", The Science of the Total Environment, Vol. 560-561, pp. 82-91.

Georghiou, L. (2007), "Future of foresighting for economic development”, working paper, UNIDO Expert Group Meeting on the Future of Technology Foresight, Vienna, Austria, 29 and 30 May.

Loveridge, D. (2008), Foresight: The Art and Science of Anticipating the Future, Routledge, London.

Mattila, T. and Riina, A. (2011), "Backcasting sustainable freight transport systems for Europe in 2050", Energy Policy, Vol. 39 No. 3, pp. 1241-1248.

Meissner, P. and Wulf, T. (2013), "Cognitive benefits of scenario planning: its impact on biases and decision quality", Technological Forecasting and Social Change, Vol. 80 No. 4, pp. 801-814. 
Mintzberg, H., Bruce, A. and Joseph, L. (2005), Strategy Safari: A Guided Tour through the Wilds of Strategic Management, Simon and Schuster, New York, NY.

Ministry of Economy, Trade, and Industry (METI) (2006), "Technology strategy map 2006", working paper, Japanese Government, Tokyo, 1 April.

New Energy and Industrial Technology Development Organization (NEDO) (2007), Gijutu Senryaku Mappu 2 Toshi to Koutsuu Infura 2025 Nen Toshi to Koutsuu Infura Ga Kawaru?, pamphlet, NEDO, Kawasaki, Japan.

Phadnis, S., Caplice, C., Sheffi, Y. and Singh, M. (2015), "Effect of scenario planning on field experts' judgment of long-range investment decisions", Strategic Management Journal, Vol. 36 No. 9, pp. 1401-1411.

Robinson, J. (2003), "Future subjunctive: backcasting as social learning", Futures, Vol. 35 No. 8, pp. 839-856.

Saka A., Igami M. and Kuwahara T. (2010) (Eds) "Saiensu mappu 2008: ronbun detabesu bunseki (2003nen Kara 2008-nen) ni yoru chūmoku sareru kenkyū ryōiki no dōkō chōsa [science map 2008: a survey about the development of science areas on the basis of a database analysis of scientific papers (2003-2008)]", NISTEP Report No. 139. Tokyo, Japan.

Saritas, O. (2015), "Systemic foresight methodology", in D. Meissner, et al. (Ed.) Science, Technology, a Innovation Policy for the Future, Springer, Heidelberg New York, NY Dordrecht London, pp. 83-117.

Saritas, O. and Smith, J.E. (2011), "The big picture-trends, drivers, wild cards, discontinuities and weak signals", Futures, Vol. 43 No. 3, pp. 292-312.

Science \& Technology Foresight Center (2015), "Horizon scanning ni mukete", STI Horizon, Vol. 1 No. 1, pp. 13-17.

Takahashi, R., Nakamura, R. and Washida, Y. (2019), "Socio-technological scenarios of Japan's future energy issues in 2050 based on scanning-based foresight method", foresight, Vol. 21 No. 4, pp. 467-481.

The Deloitte Centre for Health Solutions (2014), Healthcare and Life Sciences Predictions 2020, Deloitte LLP, London.

The Economic Planning Agency Planning Bureau (1991), Technological Forecasting in 2010. Evaluation of Impact Given to Industry and Economy by Future Technology: Technological Forecasting Study Association Report in 2010, Ministry of Finance Printing Bureau, Tokyo, Japan.

Udagawa, M. and Hanazato, T. (2001), Dai 7 Kai Monbu Kagaku Sho Gijutu Yosoku Chousa 2030 Nen No Kagaku Gijutu (Gaiyou), Institute for Future Engineering, Tokyo, Japan.

Wack, P. (1985), "Scenarios: uncharted waters ahead", Harvard Business Review, Vol. 63 No. 5, pp. 73-89.

Washida, Y., Mitsuishi, S. and Horii, H. (2009), "A future scenario generation experiment in sociotechnological problems using scanning method", Sociotechnica, Vol. 6, pp. 1-15.

\section{Corresponding author}

Yuichi Washida can be contacted at: b101348r@r.hit-u.ac.jp

For instructions on how to order reprints of this article, please visit our website: www.emeraldgrouppublishing.com/licensing/reprints.htm

Or contact us for further details: permissions@emeraldinsight.com 